\title{
Folie á Deux: Two Case Reports
}

Mohammad Y. Abu-Salha M.D.

Eastern Virginia Medical School, Norfolk, VA

Follow this and additional works at: https://jdc.jefferson.edu/jeffjpsychiatry

Part of the Psychiatry Commons

Let us know how access to this document benefits you

\section{Recommended Citation}

Abu-Salha, Mohammad Y. M.D. (1998) "Folie á Deux: Two Case Reports," Jefferson Journal of Psychiatry. Vol. 14 : Iss. 1 , Article 3.

DOI: https://doi.org/10.29046/JJP.014.1.002

Available at: https://jdc.jefferson.edu/jeffjpsychiatry/vol14/iss1/3

This Article is brought to you for free and open access by the Jefferson Digital Commons. The Jefferson Digital Commons is a service of Thomas Jefferson University's Center for Teaching and Learning (CTL). The Commons is a showcase for Jefferson books and journals, peer-reviewed scholarly publications, unique historical collections from the University archives, and teaching tools. The Jefferson Digital Commons allows researchers and interested readers anywhere in the world to learn about and keep up to date with Jefferson scholarship. This article has been accepted for inclusion in Jefferson Journal of Psychiatry by an authorized administrator of the Jefferson Digital Commons. For more information, please contact: JeffersonDigitalCommons@jefferson.edu. 


\title{
Folie á Deux
}

\section{Two Case Reports}

\author{
Mohammad Abu-Salha, M.D. \\ and Rajinder S. Dhillon, M.D.
}

\begin{abstract}
Two cases of "Shared Psychotic Disorder" were diagnosed over a period of less than a year in a children's psychiatric center. ${ }^{1}$ Shared Psychotic Disorder is one of the differential diagnoses that need to be entertained when evaluating a delusional patient. Including the patient's family and/or significant others in the assessment increases the possibility of diagnosing Shared Psychotic Disorder. An eight-year-old girl was admitted after exhibiting psychotic behavior with paranoid delusions she shared with her mother. Specifically, she reported that "neighbors next door were repeatedly breaking into her house, pinning her down, raping her, and injecting her with I.V. drugs." An eight-year-old boy also shared a paranoid delusional system with his mother. Both believed that the public school system targeted the boy, abusing him both physically and mentally in an effort to destroy him.
\end{abstract}

\section{INTRODUCTION}

Shared psychotic disorder ( folie á deux) or "insanity of two," was first described in 1860 by Jules Baillarger who named the disorder "folie á communiquee," yet, the first description is usually attributed to Laségue and Falret (1877). 1,2 Shared psychotic disorder (SPD) is the most recent of a long list of names which included induced insanity, contagious insanity, insanity by association, induced psychotic disorder, and shared delusional disorder. Like most psychiatric phenomena, SPD was also the theme of a well known movie, Cries and Whispers, by Ingmar Bergman, ${ }^{3}$ in which a nurse is inexorably drawn into the psychosis of her patient. The disorder may be shared by more than two people and thus the terms folie á trois, folie á quatre, folie á cinq, etc. ${ }^{1}$ SPD, a relatively rare syndrome, has long attracted the clinical attention of researchers trying to explain the seemingly contagious nature that a delusional system may have. In 1988, Sacks postulated that the disorder is more frequent than usually thought, especially when hospitalized patients are evaluated with their families. ${ }^{3}$ Shared Psychotic Disorder is usually diagnosed in the context of relationships in which one individual affects the other. In most instances, psychotic symptoms develop in a patient during a close long term relationship with another person who had a preexisting psychotic disorder, with the former being considered the secondary 
case (Inductee or Recipient), and the latter being considered the primary case, (Inducer). ${ }^{4}$

The delusions shared are usually persecutory in nature. ${ }^{14}$ Both patients usually live in close proximity and are often isolated from the outside world and its influences. ${ }^{4}$ Even before this syndrome was assigned a nomenclature, William Harvey (1651) described a case of "phantom pregnancy" associated with a folie á deux in two sisters who both believed that they could frequently feel the movement of the child as they occupied the same bed. ${ }^{5}$ The diagnostic criteria evolved over the years into the current DSM IV formulation (Table 1$).^{6}$

Different subtypes ${ }^{4}$ of the disorder have been described depending on the nature of the relationship between the two patients forming the dyad. In folie imposee, the most common subtype, the dominant (inducing) person has a true psychosis, whereas the recipient (inductee) does not, but is submissive and suggestible. Separation of the two people may cause the recipient to give up the delusions.

In folie simultanee, ${ }^{7}$ delusions occur simultaneously in two individuals predisposed to the development of a true psychotic illness who are closely related and share a delusional system. Separation of the two does not lead to improvement in either. In folie induite, an individual often hospitalized for psychosis will adopt the delusions of another patient and add them to his delusional system. In folie communiquee, both patients have true psychotic disorder but the appearance of symptoms in the submissive person usually follows those of the dominant person. Of the above mentioned subtypes, only folie imposee and folie communiquee meet DSM IV criteria.

TABLE 1.

\section{Diagnostic Criteria for SPD (DSM IV)}
A. A delusion develops in an individual in the context of a close relationship with another person(s), who has an already established delusion.
B. The delusion is similar in context to that of the person who already has the established delusion.
C. The disturbance is not better accounted for by another psychotic disorder (e.g. schizophrenia) or a mood disorder with psychotic features and is not due to the direct physiological effect of a substance (e.g. a drug of abuse, a medication) or a general medical condition.

\section{CASE 1}

An eight year old girl was admitted to a psychiatric center after exhibiting acute psychosis manifested by agitation, confusion, paranoid delusions, and hallucinations with inability to care for herself. Emergency staff was contacted by the care taker and the patient was urgently admitted.

When interviewed, the patient voiced that her neighbors had been repeatedly breaking into the house she and her mother shared. She also believed that on different occasions these neighbors pinned her down, raped her, and injected her with I.V. drugs, cocaine, and rat poison. She could hear their voices in the house while they committed these acts, and she recalled 
seeing them at different times. The patient showed the examiner her left arm (which was unmarked in any way) trying to have him see the needle tracks. Prior to admission, the patient suffered from insomnia, felt afraid of going to bed, and complained of "scary nightmares." Her social skills, behavior, and hygiene were reported to have been deteriorating over several days prior to admission.

On mental status examination the patient was an apparently healthy looking, acceptably groomed eight year old girl who was fully alert and oriented with no psychomotor or speech abnormality. Her mood was depressed, and affect was blunted, and restricted. She acknowledged the above mentioned hallucinations and delusions as noted. She denied suicidal or homicidal ideation. Despite the paranoid content of her thoughts, she showed normal thought processing and intact abstraction, consistent with her age. There was no cognitive impairment or memory deficit. Intelligence was within normal limits and her general fund of knowledge was fair. Her insight and judgment were impaired at the time of admission.

The patient had no history of psychiatric or medical illness according to her family and her primary care physician. Her developmental history was within normal limits and her performance in school was satisfactory prior to this illness. Psychosocial history was significant for a foster home placement from ages 2 to 4 years when her mother was "ill" and unable to take care of her. For the last few years the patient had been living with her widowed mother (her father had died of drowning when she was an infant). The patient and her mother led an isolated life, seemingly in an excessively close relationship. They both denied that the patient was ever physically or sexually abused.

When trying to contact the mother, the examiner was informed that the patient's mother admitted herself to the adult unit at the same psychiatric center shortly after her daughter's admission. The mother informed her psychiatrist that for the last few months and after moving to their current neighborhood their neighbors had been repeatedly breaking into their house, raping her daughter, and injecting both of them with I.V. drugs which caused the mother's limbs and body to swell up. She also voiced the same auditory and visual hallucinations as reported by her daughter. The patient's mother was vague about her previous history of psychiatric illness, but upon reviewing her records, it was noted that from 1989 to 1996 she had made fourteen visits to the emergency department of a local general hospital complaining of similar symptoms (in addition to her chronic pelvic inflammatory disease). The mother always refused psychiatric assessment or treatment. She even reported her complaints recurrently to a local police station but their nonspecific and vague content could not be verified by the police.

After full assessment, a physical examination, including a gynecological examination, revealed no signs of genital trauma. A complete laboratory work up (including urine drug screen) was within normal limits. The daughter was diagnosed with Shared Psychotic Disorder and the mother was diagnosed with Psychotic Disorder Not Otherwise Specified.

Being separated from her mother, the patient improved remarkably, benefiting from individual and group therapy. She was discharged one week later to the custody of a friend of her family agreed upon by her mother. The department of social services was informed of the mother's illness and follow-up was arranged to ensure that the mother would seek and comply with treatment in order to be allowed supervised contact with the daughter.

\section{CASE 2}

An eight year old boy under the custody of the department of social services and carrying a diagnosis of Attention Deficit-Hyperactivity Disorder was admitted to a psychiatric facility for exhibiting aggressive, dangerous, destructive, assaultive, and threatening behavior. The 
patient could not be managed by the foster home family (his third placement in one year). The patient admitted to feeling sad, depressed, hopeless, helpless, and worthless but denied any suicidal/homicidal ideation or any hallucinations. The patient had had two previous psychiatric hospitalizations while he was in the custody of his biological mother, a 46 year old divorced woman who had a teaching degree, but had been unemployed since the birth of her son.

Further history revealed that the patient had been aggressive, impulsive, and unmanageable in the two previous foster homes. While investigating the causes for the relapse and the history of previous relationship with the mother, the examiner found out that the patient had conduct problems at school and that in 1994 he attacked another student in class for "picking on" a female friend of his.

Medical records revealed that the mother lost custody of her son prior to the last admission for refusing to send him to school because "he was not getting any education there" and "the public school system was unsafe and run by mentally retarded people who didn't know how to teach". She claimed that the patient was repeatedly mistreated both physically and verbally by students and teachers who treated him like a "prisoner". The mother used derogatory and obscene language in her description. The patient shared these beliefs and frequently came back from school to tell her that he was abused, beaten up, molested, and humiliated in school. The patient's mother complained to the school officials that the patient was "targeted" by the public school system which was trying to "destroy him".

The mother quit her job as a teacher after the patient's birth. Their relationship was close and isolated, with both living on welfare and food stamps. The patient didn't recall his father whom his mother described as "schizophrenic". The patient and his mother denied any history of physical or sexual abuse.

After a complete assessment, including a physical examination which revealed no abnormal findings, the patient was therapeutically separated from his mother, who was allowed to visit him once a week and was ordered by the court to seek psychiatric evaluation and management before she would be considered again for custody. The patient was maintained on methylphenidate and imipramine, and also started on a small dose of risperidone. He responded dramatically and was discharged and followed up as an outpatient. He did well and resumed school with a fairly reasonable performance.

\section{DISCUSSION}

These two cases are consistent with the fact that in SPD, delusions are shared between two individuals enmeshed in a dysfunctional relationship in which the submissive person, in the context of possible fear of abandonment and social isolation, adopts the delusions of the dominant partner. Object relations theorists have postulated that an individual may be in a state of psychological fusion or may share a dyadic space with the person, in which case self and object are emotionally indistinguishable. ${ }^{8}$

Another view is that the recipient may have repressed oedipal fantasies that are unleashed by the dominant partner's initiative so that the inducer becomes identified in the mind of the recipient with one or the other parent, yet in both cases reported above, the inducer was the patient's mother. ${ }^{8}$ The classical learning theory model suggested by Schmidt proposes that the recipient learns the abnormal behavior from the dominant inducer and so begins to think and behave the same way. ${ }^{9,10}$ Anthony ${ }^{11}$ 
suggested that, in stressful circumstances, adults who have experienced disturbances in the separation-individuation process succumb more easily to a regression to magical thinking when they adopt the "reality" of the inducer who, in this case, represents the parent. A case report of folie a famille was published ${ }^{12}$ in which SPD involved a family of two parents and their two adolescent children. The authors explained this psychopathy from a "system theory" perspective applying the concept of "circular causality," suggesting that once the recipient has adopted the delusion, he/she then upholds and reinforces the thoughts of the inducer.

The bulk of psychodynamically oriented literature has theorized about the "dominance-submissiveness" aspect of the relationship. ${ }^{13}$ It was inferred that submissiveness on the part of the inductee was the function of being a woman (subject to the domination of a man), a youth (subject to the authority of an older adult), a passive person, a person with low self esteem, a person with a sensory impairment, a frail elderly person, a person suffering substance abuse or cerebrovascular disease, an individual with low intelligence, or one with a genetic predisposition to psychiatric illness. Silveira and Seeman ${ }^{14}$ reviewed published case reports from 1942 to 1993 focusing on the recipient or secondary person to whom the SPD diagnosis was applied. Findings revealed: 1) males and females were affected with equal frequency; 2) there was equal prevalence in younger and older age groups; 3) the majority of shared psychoses $(90.2 \%)$ were equally distributed among married couples, siblings, and parent-child dyads; 4) comorbid dementia, depression, and mental retardation were common; 5) hallucinations were common; 6) the majority of dyads $(67.3 \%)$ were socially isolated.

Sixteen cases published in English literature described SPD in twins. Eleven of the sixteen cases $(69 \%)$ represent the folie simultanee subtype. The majority of twins described were monozygotic twins. ${ }^{15}$ Rioux ${ }^{16}$ described a case of folie á deux in twins in which there was a long period of remission in one of the twins following the death of her sister.

In terms of management, each case must be regarded as unique and the relationship between the illness partners should be thoroughly evaluated. ${ }^{17}$ Unfortunately, few published studies have examined the outcome of different treatment approaches. ${ }^{12}$ Commonly, the inducer's primary illness is treated with antipsychotic medication and, if needed, psychiatric hospitalization. The inductee may improve after separation especially in adult-child dyads, if the inductee has an "imposed psychosis." Inductees who exhibit "communicated psychosis" and are delusional, require specific treatment in addition to separation from the inducer(s). ${ }^{3}$ Despite the popular belief that separating the two patients always proved to be effective, it actually lead to full recovery in only forty percent of cases. ${ }^{4}$ Sacks $^{3}$ argued that separation has not always proved to be efficient in treating the secondary patient, especially if she had "communicated psychosis." Treatment by separation was also questioned by Layman. ${ }^{18}$ Rioux ${ }^{16}$ reported a case of two psychotic sisters in which the secondary severely deteriorated after separation from the primary. Based on his review of the literature and the work done by Layman and Rioux, Sacks concluded that "the literature seemed to be oddly optimistic regarding the prognosis" 3 and until 
more systematic epidemiological, phenomenological, diagnostic, treatment and outcome studies are available, our understanding of this illness will be only based on anecdotal reports and clinical judgement. The extensive literature review done by Silveira and Seeman ${ }^{14}$ in 1995 did not prove otherwise.

\section{CONCLUSION}

SPD is a seldom reported entity that is likely underdiagnosed. ${ }^{3}$ Given the isolation and seclusiveness of most sufferers, there is insufficient data about the prevalence of this syndrome. It can only be diagnosed if the patient's family and/or significant others are evaluated. ${ }^{3}$ Contrary to previous expectations, there is no evidence that SPD is more frequent among females or in the younger member of the dyad. ${ }^{14}$ Many theories have been proposed to explain the psychodynamics of this disorder. Separation of the two patients forming the dyad proved effective only in forty percent of the cases. ${ }^{4}$ More systematic epidemiological, diagnostic, treatment and outcome studies are needed in order to improve our understanding and management of SPD.

\section{REFERENCES}

1. Kaplan HI, Sadock BJ: Comprehensive Textbook of Psychiatry. Ed. 6, Vol. 1. Williams and Wilkins; Baltimore 1995; P. 1047.

2. Laségue C, Falret J: Folie á Deux ou Folie Communique. Ann Med Psychology 1877; 18; 321 (Translated by Michaud R.) Am J Psychiatry 1964; 121 (4 suppl): 2s-23s.

3. Sacks MH: Folie á Deux. Compr. Psychiatry. Vol. 29, No. 3. (May/June) 1988. pp. 270-277.

4. Howard R: Induced Psychosis. British J Hosp Medicine, 51 (6): 305; 1994.

5. Hunter R and Macalpine I. (1963). Three hundred years of psychiatry. Oxford University Press, London.

6. Diagnostic and Statistical Manual of Mental Disorders. 4th edition, (DSM IV). APA. Washington, 1994.

7. Regis E: Manuel pratique de medecine. Authorized translation by Bannister HM. A practical manual of mental medicine. 2nd Ed. Philadelphia: Blakiston, 1895.

8. Coleman S, Last S (1939). A study of folie á deux. J Ment Sci 85:1212-1223.

9. Schmidt AO (1949). A case of folie á deux. J Abnorm Soc Psychol 44:402-410.

10. Howard R: (1992). Folie á deux involving a dog. Am J Psych 149:414.

11. Anthony EJ: Folie á deux: á developmental failure in the process of separationindividuation. In: McDevit JB, Settlage CF (eds): Separation-Individuation New York, NY: International University Press, 1971. pp. 253-273.

12. Mentijox R, Van Houten CA, Koolman CG: Induced psychotic disorder: Clinical aspects, theoretical considerations, and some guidelines for treatment. Compr Psychiatry. Vol 34, No. 2 (Mar/Apr 1993): 120-126.

13. Gralnick A: Folie á Deux: the psychosis of association. Psychiatry Q 1942; 16:230-263.

14. Silvera JM, Seeman MV: Shared psychotic disorder: A critical review of the literature. Can J Psychiatry, Vol. 40, Sep. pp. 389-395. 
15. White TG: Folie simultanee in monozygotic twins. Can J Psychiatry. Vol. 40, Sep 1995. pp. 418-420.

16. Rioux B: A review of folie á deux; the psychosis of association. Psychiatric Q 1963; 37:405-428.

17. McWilliams N: Psychoanalytic diagnosis. Guilford Publications: 1994; 31.

18. Kallman FJ, Mickey JS: The concept of induced insanity in family units. J Nerv Ment Dis 1946; 104:303-315. 